\title{
MECHANISMS OF TOLERANCE INDUCTION AND PREVENTION OF CARDIAC ALLOGRAFT VASCULOPATHY IN MINIATURE SWINE: THE EFFECT OF AUGMENTATION OF DONOR ANTIGEN LOAD
}

\author{
Kazuhiko Yamada, MD \\ Kwabena Mawulawde, MD ${ }^{\mathrm{a}}$ \\ Matthew T. Menard, MD \\ Akira Shimizu, MD*b \\ H. Thomas Aretz, MD \\ Joseph K. Choo, MD \\ Kenneth S. Allison, BA ${ }^{\mathrm{a}}$ \\ Joanna K. Slisz, BA*a \\ David H. Sachs, MD \\ Joren C. Madsen, MD, DPhil ${ }^{\mathrm{a}, \mathrm{c}}$
}

Objective: Cotransplantation of a donor kidney along with a heart allograft can induce tolerance to both organs and prevent cardiac allograft vasculopathy in miniature swine. To determine whether the tolerogenic effect of donor kidney cotransplantation was due to an effect specific to the kidney graft or to an increase in donor antigen load, we compared heart-kidney recipients with recipients receiving two class I disparate hearts or with recipients receiving donor peripheral mononuclear cells at the time of isolated heart transplantation.

Methods: Recipients of major histocompatibility complex class I disparate allografts received 12 days of cyclosporine (INN: ciclosporin; 10-13 mg/kg administered intravenously on days $0-11$ ). Group 1 animals received a heart alone $(n=5)$. Group 2 animals received heart and kidney allografts $(n=4)$. Group 3 animals received two major histocompatibility complex-matched heart allografts $(n=4)$. Two double-heart recipients were thymectomized 21 days before transplantation. Group 4 animals received a heart allograft and an infusion of high-dose donor peripheral blood leukocytes $\left(2.5 \times 10^{9}\right.$ cells/kg, $\mathrm{n}=2$ ).

Results: Vasculopathy developed in group 1 recipients and the allografts were rejected within 55 days. Group 2 recipients accepted their heart and kidney allografts indefinitely without vasculopathy. Euthymic recipients from group 3 accepted their hearts long-term (>190 and >197 days), but vascular lesions developed. In thymectomized recipients from group 3, the hearts were rejected in 63 and 96 days with severe vasculopathy. Group 4 recipients demonstrated transient macrochimerism but their hearts were rejected within 47 and 63 days.

Conclusions: The beneficial effects of donor kidney cotransplantation on cardiac allograft survival and prevention of cardiac allograft vasculopathy are likely to involve both an increase in donor antigen load and an effect specific to the kidney allograft. (J Thorac Cardiovasc Surg 2000;119:709-19)
Exp xerimental studies investigating the mechanisms and treatment of cardiac allograft vasculopathy (CAV) have been primarily performed in rodents. Although these studies have yielded many important findings, the profound biologic differences that exist

From the Transplantation Biology Research Center, ${ }^{a}$ the Department of Pathology, ${ }^{\mathrm{b}}$ and the Division of Cardiac Surgery, ${ }^{\mathrm{c}}$ Massachusetts General Hospital, Harvard Medical School, Boston, Mass.

Supported in part by grants from the National Heart, Lung, and Blood Institute of National Institutes of Health (RO1-HL54211) and The Thoracic Surgery Foundation for Research and Education. Dr Menard is an Edward D. Churchill Surgical Research Fellow, Massachusetts General Hospital.

Received for publication Aug 26, 1999; revisions requested Oct 27, 1999; revisions received Nov 18, 1999; accepted for publication Nov 23, 1999. between rodents and human beings have suggested the need for a large animal model of CAV. To this end, a heterotopic heart transplantation system has been developed and validated to study the pathogenesis and treatment of CAV in partially inbred miniature swine. ${ }^{1}$ In

\footnotetext{
Address for reprints: Joren C. Madsen, MD, DPhil, Massachusetts General Hospital, Department of Surgery, EDR 105, Boston, MA 02114.

* Dr Shimizu is currently affiliated with the Department of Pathology, Nippon Medical School, Tokyo, Japan. Ms Slisz is currently affiliated with the Department of Biology, University of Connecticut, Storrs, Conn.

Copyright (C) 2000 by The American Association for Thoracic Surgery

$0022-5223 / 2000 \$ 12.00+0 \quad \mathbf{1 2 / 1 / 1 0 4 5 7 8}$

doi: $10.1067 / \mathrm{mtc} .2000 .104578$
} 
contrast to the profound differences between rodents and human beings, the immune system and cardiovascular system of swine closely resemble those of human beings, ${ }^{2,3}$ as does their susceptibility to nontransplant ${ }^{4}$ and transplant atherosclerosis. ${ }^{5}$

In contrast to rodent systems, ${ }^{6-8}$ major histocompatibility complex (MHC) class I antigens appear to play an important role in the early development of vascular lesions in miniature swine. ${ }^{1,9}$ Thus, when MHC class I-disparate hearts were transplanted into porcine recipients treated with a short course of cyclosporine A (INN: ciclosporin; CyA), they all experienced the florid intimal proliferation of $\mathrm{CAV}$ by postoperative day (POD) 28 and went on to full rejection within 55 days. ${ }^{10}$ To determine whether the induction of tolerance to donor class I antigens in the host could prevent the development of CAV, porcine recipients were cotransplanted with the heart and kidney from the same class I disparate donor. The rationale for this approach grew out of earlier studies showing that in contrast to heart allografts CyA-treated recipients bearing isolated class I disparate kidneys all became tolerant to donor antigen and maintained excellent long-term renal function. ${ }^{11,12}$ When miniature swine were cotransplanted with the heart and kidney from the same class I disparate donor, they experienced rapid and stable tolerance to the donor that not only led to the long-term survival of the heart allografts but also avoided the development of CAV, thus demonstrating that acquired tolerance can prevent chronic rejection in this large animal model. ${ }^{10}$

The mechanism by which tolerance is induced in porcine recipients of heart plus kidney allografts and how this acquired tolerance prevents the development of CAV remains unclear. One hypothesis is that the donor kidney induces or transfers specific regulatory $\mathrm{T}$ cells to the host, which act centrally, peripherally, or both to induce tolerance. ${ }^{13} \mathrm{~A}$ competing hypothesis is that the kidney allograft simply confers more donor antigen to the host and that this augmentation of donor antigen results in antigen-induced specific unresponsiveness. ${ }^{14}$ To determine whether the beneficial effects of donor kidney cotransplantation on cardiac allograft survival was due to an effect specific to the kidney graft or to an increase in total donor antigen load, we compared recipients receiving heart and kidney allografts to recipients transplanted with two class I disparate hearts or to recipients receiving donor peripheral mononuclear cells at the time of isolated heart transplantation. We present data here indicating that although augmentation of donor-antigen load is important, it does not appear to be the sole mechanism by which transplantation of a kidney induces tolerance to a heart allograft and thereby prevents $\mathrm{CAV}$.

\section{Methods}

Animals. Partially inbred miniature swine (age, 4-10 months; weight, 20-50 kg) were used as transplant donors and recipients. The characteristics of miniature swine have been described previously. ${ }^{15}$ Recombinant SLAgg (class $\mathrm{I}^{\mathrm{c}} / \mathrm{II}^{\mathrm{d}}$ ) swine were used as heart and kidney donors, and $\mathrm{SLA}^{\mathrm{dd}}$ (class $\mathrm{I}^{\mathrm{d} / \mathrm{II}^{\mathrm{d}}}{ }^{\text {) }}$ animals were used as recipients to achieve a 2-haplotype MHC class I mismatch. ${ }^{10}$ All recipients demonstrated significant in vitro antidonor cytotoxic activity (>20\% specific lysis) before organ transplantation. All animal care and procedures were in compliance with the "Principles of Laboratory Animal Care" formulated by the National Society for Medical Research and the "Guide for the Care and Use of Laboratory Animals" prepared by the Institute of Laboratory Animal Resources, National Research Council, and published by the National Academy Press, revised 1996.

Surgical procedures. A semipermanent indwelling silicone rubber central venous catheter was placed into the external jugular vein of recipients to facilitate $\mathrm{CyA}$ administration and frequent blood sampling for monitoring of renal function, whole blood CyA levels, and in vitro assays. The surgical procedures used for heart transplantation, kidney transplantation, and combined heart-kidney transplants have been described in detail previously. ${ }^{1,10,16}$ Juvenile donors and recipients were anesthetized with ketamine $(20 \mathrm{mg} / \mathrm{kg})$, halothane $1 \%$, nitrous oxide $1 \%$, and oxygen. Through either a retroperitoneal or transperitoneal approach, the infrarenal aorta and inferior vena cava were isolated. After the recipient had been systemically heparinized $(3 \mathrm{mg} / \mathrm{kg})$, heterotopic heart transplantation was performed on the right side of the great vessels by anastomosing the donor pulmonary artery end to side to the recipient inferior vena cava and then anastomosing the donor ascending aorta end to side to the recipient abdominal aorta. An atrial septal defect was created in the donor heart, and the mitral valve was defunctionalized to minimize left ventricular atrophy and intracavitary thrombus formation. ${ }^{17}$ Iridiumtipped ventricular electrodes (model 6500 pacing lead; Medtronic Inc, Secaucus, NJ) were implanted in the myocardium of each ventricle and brought out through the skin for long-term electrocardiographic monitoring. In some cases, heart transplantation was followed by transplantation of a kidney (combined heart-kidney transplant) or a second heart (double-heart transplant) 1 to $2 \mathrm{~cm}$ below the cardiac allograft on the left. After blood flow to the cardiac allograft had been re-established, kidney transplantation was performed by anastomosing the donor renal artery end to side to the recipient aorta and then anastomosing the donor renal vein end to side to the recipient inferior vena cava below the level of the heart allograft. The renal transplant was completed by performing a vesicoureteral anastomosis. The second heart was transplanted in the manner described above. Two SLAgg donors were used for each double-heart transplant recipient $\left(\mathrm{SLA}^{\mathrm{dd}}\right)$. In some cases a total thymectomy, described in 
detail elsewhere, ${ }^{13}$ was carried out through a median sternotomy 21 days before double-heart transplantation.

Peripheral blood leukocyte leukopheresis and infusion. Peripheral blood leukocytes (PBLs) were obtained from donor animals by using the COBE Spectra Apheresis System (serial No. 1S03226; COBE BCT Inc, Lakewood, Colo). Two semipermanent silicone rubber central venous catheters were placed in the internal jugular veins for venous access. A total of 3 blood volumes were circulated through the system, which yielded an average volume of $244 \mathrm{~mL}$ of PBLs. Three milliliters of the cell suspension was removed, washed in Hanks' buffered saline solution (HBSS), and counted after diluting with trypan blue stain. In some recipients $2.5 \times 10^{9}$ fresh donor PBLs per kilogram (recipient body weight) were infused intravenously immediately after the heart transplant procedure had been completed and hemostasis had been obtained.

Immunosuppression. CyA (Sandimmune) was generously provided by Novartis Pharmaceutical Corporation (Hanover, $\mathrm{NJ})$ and was mixed and administered as an intravenous suspension according to the specifications of the manufacturer. CyA was given daily as a single infusion at a dose of 10 to 13 $\mathrm{mg} / \mathrm{kg}$ (adjusted to maintain a whole blood trough level of $400-800 \mathrm{ng} / \mathrm{mL}$ ) for 12 consecutive days, starting on the day of transplantation (POD 0). CyA levels were determined by means of a fluorescence polarization immunoassay (Abbott Laboratories, North Chicago, Ill), which measured parent compound but not metabolites.

Rejection monitoring. Heart function was monitored by using transabdominal palpation, electrocardiography (EK/5A, Burdick Corp, Milton, Wis), and echocardiography (Sonos 1500; Hewlett-Packard Company, Andover, Mass). Kidney function was monitored by means of serum creatinine levels. Cardiac allograft rejection (heart survival time) was defined by either the loss of a ventricular impulse on palpation, an R-wave amplitude of less than $3 \mathrm{~mm}$ on epicardial electrocardiography, and/or the lack of ventricular contraction on echocardiography. ${ }^{1}$ Renal allograft rejection was defined as the death (or need for euthanasia) of the recipient because of terminal uremia. Allograft rejection was confirmed histologically in all cases.

Histology. Sequential heart, kidney, or both types of allograft biopsies were performed on PODs $8,14,18$ to 21,28 to 30,50 , and $>100$. Open biopsy specimens of the transplanted heart and kidney were obtained by using a Tru-Cut needle (Baxter, Deerfield, Ill) or wedge biopsies. Coded histologic specimens were stained by using hematoxylin and eosin, Masson's trichrome, and periodic acid-Schiff staining and scored under light microscopy by a blinded observer to determine the severity of acute rejection and the degree of intimal proliferation. Scoring of acute rejection in the heart allograft was based on the International Society for Heart and Lung Transplantation classification. ${ }^{18}$ The degree of arterial intimal thickening was scored from 0 (normal artery) to $3(>50 \%$ luminal occlusion) on the basis of a modification of the system described by Lurie and colleagues. ${ }^{1,19}$ The average grade of intimal thickening of all small, medium, and large arterial vessels examined from each heart at necropsy was designat- ed the mean average involvement score $^{6}$ and recorded. Kidney allograft rejection was scored by means of standard pathologic criteria described elsewhere. ${ }^{20}$ Heart and kidney biopsy specimens were also evaluated for alloantibody deposition by direct immunofluorescence staining. Frozen tissue sections were stained with a saturating concentration of a fluorescence isothiocyanate (FITC)-labeled goat anti-swine immunoglobulin (Ig) M or IgG and evaluated by fluorescence microscopy.

Preparation of PBLs for in vitro assays. Freshly heparinized whole blood was diluted approximately 1:2 with HBSS (Gibco BRL, Grand Island, NY), and the mononuclear cells were obtained by means of gradient centrifugation with lymphocyte separation medium (Organon; Teknika, Durham, NC). The mononuclear cells were washed once with HBSS, and contaminating red cells were lysed with ammonium chloride potassium lysing buffer (Bio Whittaker, Inc, Walkersville, Md). Cells were then washed with HBSS and resuspended in tissue culture medium. All cell suspensions were kept at $4^{\circ} \mathrm{C}$ until used in cellular assays.

Cell-mediated lymphocytotoxicity assay. Cell-mediated lymphocytotoxicity (CML) assays with porcine cells have been described previously. ${ }^{21}$ The tissue culture media used for the CML assays consisted of RPMI-1640 (Gibco BRL) supplemented with 6\% fetal calf serum (Sigma Chemical Co, St Louis, Mo), $100 \mathrm{U} / \mathrm{mL}$ penicillin, $135 \mathrm{mg} / \mathrm{mL}$ streptomycin (Gibco BRL), $50 \mathrm{mg} / \mathrm{mL}$ gentamicin (Gibco BRL), 10 $\mathrm{mmol} / \mathrm{L} \quad N$-2-hydroxyethylpiperazine- $N$-2-ethanesulfonic acid (HEPES; Fisher Scientific, Pittsburgh, Pa), $2 \mathrm{mmol} / \mathrm{L} \mathrm{L}-$ glutamine (Gibco BRL), $1 \mathrm{mmol} / \mathrm{L}$ sodium pyruvate (Bio Whittaker, Inc), nonessential amino acids (Bio Whittaker, Inc), and $5 \times 10^{-5} \mathrm{~mol} / \mathrm{L} \beta_{2}$-mercaptoethanol (Sigma Chemical). The effector phase of the CML assay was performed with Basal Medium Eagle (Gibco BRL) supplemented with $6 \%$ controlled processed serum replacement 3 (Sigma Chemical) and $10 \mathrm{mmol} / \mathrm{L}$ HEPES. Briefly, lymphocyte cultures containing $4 \times 10^{6} / \mathrm{mL}$ responder and $4 \times$ $106 / \mathrm{mL}$ stimulator PBLs (irradiated with $2500 \mathrm{cGy}$ ) were incubated for 6 days at $37^{\circ}$ in $7.5 \%$ carbon dioxide and $100 \%$ humidity in CML medium. Bulk cultures were harvested, and effectors were tested for cytotoxic activity on chromium 51-labeled (Amersham, Arlington Heights, Ill) lymphoblast targets. Effector cells were incubated for 5.5 hours with target cells at effector/target ratios of 100:1, 50:1, 25:1, and 12.5:1. Three target cells were tested in each assay: (1) PBLs SLA matched to the responders (negative control), (2) PBLs SLA matched to the donor (SLA ${ }^{\mathrm{gg}}$ : class $\mathrm{I}^{\mathrm{cc}}$ and class $\mathrm{II}^{\mathrm{dd}}$ ), and (3) third-party PBLs. Supernatants were then harvested by using the Skatron collection system (Skatron, Sterling, Va), and ${ }^{51} \mathrm{Cr}$ release was determined on a gamma counter (Micromedics, Huntsville, Ala). The results were expressed as a percentage of specific lysis and calculated as follows:

Percentage of specific lysis $=$

Experimental release (cpm) - Spontaneous release (cpm)

Maximum release (cpm) - Spontaneous release (cpm) $\times 100$ 
Table I. Graft survival, interstitial rejection, and intimal thickening in donor cardiac allografts

\begin{tabular}{|c|c|c|c|c|c|c|c|c|c|}
\hline \multirow[b]{2}{*}{ Group } & \multirow[b]{2}{*}{ Thymectomy } & \multirow{2}{*}{$\begin{array}{c}\text { Animal } \\
\text { identification No. }\end{array}$} & \multirow[b]{2}{*}{ Rejection } & \multicolumn{5}{|c|}{ Histology } & \multirow[b]{2}{*}{ Survival $(d)$} \\
\hline & & & & $3 w k$ & $4 w k$ & $9 w k$ & $>12 w k$ & $P M^{\S}$ & \\
\hline \multirow[t]{10}{*}{ Isolated heart } & No & $11065^{*}$ & Vascular $^{\dagger}$ & & 3 & & & 3 & 35 \\
\hline & & & Interstitial $^{\ddagger}$ & & 4 & & & 4 & \\
\hline & & $11613^{*}$ & Vascular & & 1 & & & 1 & 33 \\
\hline & & & Interstitial & & $3 b$ & & & $3 b$ & \\
\hline & & $11168^{*}$ & Vascular & & 1 & & & 3 & 45 \\
\hline & & & Interstitial & & 2 & & & $3 a$ & \\
\hline & & $11749^{*}$ & Vascular & & 2 & & & 3 & 55 \\
\hline & & & Interstitial & & $1 b$ & & & $3 b$ & \\
\hline & & $11776^{*}$ & Vascular & & 2 & & & 3 & 47 \\
\hline & & & Interstitial & & $3 a$ & & & 4 & \\
\hline \multirow[t]{8}{*}{ Heart and kidney } & No & $11982^{*}$ & Vascular & & 0 & 0 & 0 & 0 & $>179$ \\
\hline & & & Interstitial & & $1 \mathrm{~b}$ & 1a & $1 \mathrm{a}$ & 1a & \\
\hline & & $12232^{*}$ & Vascular & & 0 & 0 & 0 & 0 & $>269$ \\
\hline & & & Interstitial & & $1 \mathrm{a}$ & 0 & 0 & 0 & \\
\hline & & $12333^{*}$ & Vascular & & 0 & 0 & 0 & 0 & $>261$ \\
\hline & & & Interstitial & & $1 b$ & 0 & 0 & 0 & \\
\hline & & 12614 & Vascular & & 0 & & 0 & 0 & $>200$ \\
\hline & & & Interstitial & & 0 & & 0 & 0 & \\
\hline \multirow[t]{8}{*}{ Double heart } & No & 12240 & Vascular & & 1 & 1 & 1 & 1 & $>190$ \\
\hline & & & Interstitial & & $2 \mathrm{a}$ & $2 \mathrm{a}$ & 1a & 1a & \\
\hline & & 12366 & Vascular & & 1 & 1 & 2 & 2 & $>197$ \\
\hline & & & Interstitial & & $3 a$ & $2 \mathrm{a}$ & $1 \mathrm{a}$ & $1 \mathrm{a}$ & \\
\hline & Yes & 12688 & Vascular & & & 3 & & 3 & 63 \\
\hline & & & Interstitial & & & 4 & & 4 & \\
\hline & & 12949 & Vascular & & 3 & 2 & & 2 & 96 \\
\hline & & & Interstitial & & $3 a$ & $3 b$ & & $4 a$ & \\
\hline \multirow[t]{4}{*}{ Heart and PBL } & No & 12922 & Vascular & & $-^{\prime \prime}$ & 1 & & 1 & 63 \\
\hline & & & Interstitial & & $3 a$ & 4 & & 4 & \\
\hline & & 12952 & Vascular & & - & 2 & & 2 & 47 \\
\hline & & & Interstitial & & $3 b$ & $3 b$ & & $3 b$ & \\
\hline
\end{tabular}

${ }^{*}$ The results of these control animals have been reported previously. ${ }^{10}$

${ }^{\dagger}$ Small and large arteries were graded on the basis of a scoring system modified from that of Lurie and colleagues. ${ }^{19}$ The average score of all involved vessels was rounded to the nearest whole number.

Grading on the basis of the International Society for Heart and Lung Transplantation scoring system. ${ }^{18}$

${ }^{\S}$ Represents either the most recent biopsy or the necropsy specimen.

"Insufficient number of arteries in specimen.

Flow cytometry. The presence of antidonor class I (SLA class $\left.\mathrm{I}^{\mathrm{cc}}\right) \operatorname{IgM}$ and $\mathrm{IgG}$ in the serum of swine was detected by means of indirect flow cytometry with a Becton Dickinson FACScan microfluorimeter (Sunnyvale, Calif) by using recombinant SLA PBLs to determine the SLA-binding specificity of the antibody. FITC-labeled goat anti-swine IgM or IgG polyclonal antibodies were used as secondary reagents (Kirkegaard \& Perry Laboratories Inc, Gaithersburg, Md). For staining, $1 \times 10^{6}$ cells per tube of donor-type PBLs $\left(\mathrm{SLA}^{\mathrm{gg}}\right.$, class $\mathrm{I}^{\mathrm{c}}$ and $\mathrm{II}^{\mathrm{d}}$ ) were resuspended in HBSS containing $0.1 \%$ bovine serum albumin and $0.05 \% \mathrm{NaN}_{3}$ and incubated for 30 minutes at $4^{\circ} \mathrm{C}$ with decomplemented test sera. After two washes, a saturating concentration of FITC-labeled goat anti-swine IgM or IgG was added and incubated for 30 minutes at $4^{\circ} \mathrm{C}$. After a final wash, cells were analyzed by means of flow cytometry with propidium iodide gating to exclude dead cells. Both normal pig serum and pretransplant sera from each experimental animal were used as controls for specific binding.

Circulating donor cells were also evaluated to assess donor macrochimerism by using flow cytometry with whole blood from the recipient. Cells were stained with optimal concentrations of directly conjugated anti-pig murine monoclonal antibodies (mAbs) 74-12-4 (IgG2b, anti-swine CD4), 76-211 (IgG2a, anti-swine CD8), 76-7-4 (IgG2a, anti-swine CD1), ${ }^{22}$ MSA4 (IgG2a, anti-swine CD2), ${ }^{23}$ 2-6-15 (IgG2a, anti-swine $\mathrm{CD} 3$; C. Huang, manuscript in preparation), 2-273a (IgG2a, anti-swine class I), ISCR-3 (IgG2a, anti-swine class II), and 16.7 (IgM, anti-SLA class $\mathrm{I}^{\mathrm{c}}$ ). Phenotype was analyzed by 2 -color staining. The staining procedure was performed as follows. One hundred microliters per tube of heparinized whole blood was incubated for 30 minutes at $4{ }^{\circ} \mathrm{C}$ with saturating concentrations of an FITC-labeled mAb. After a single wash, the secondary biotinylated antibody was 

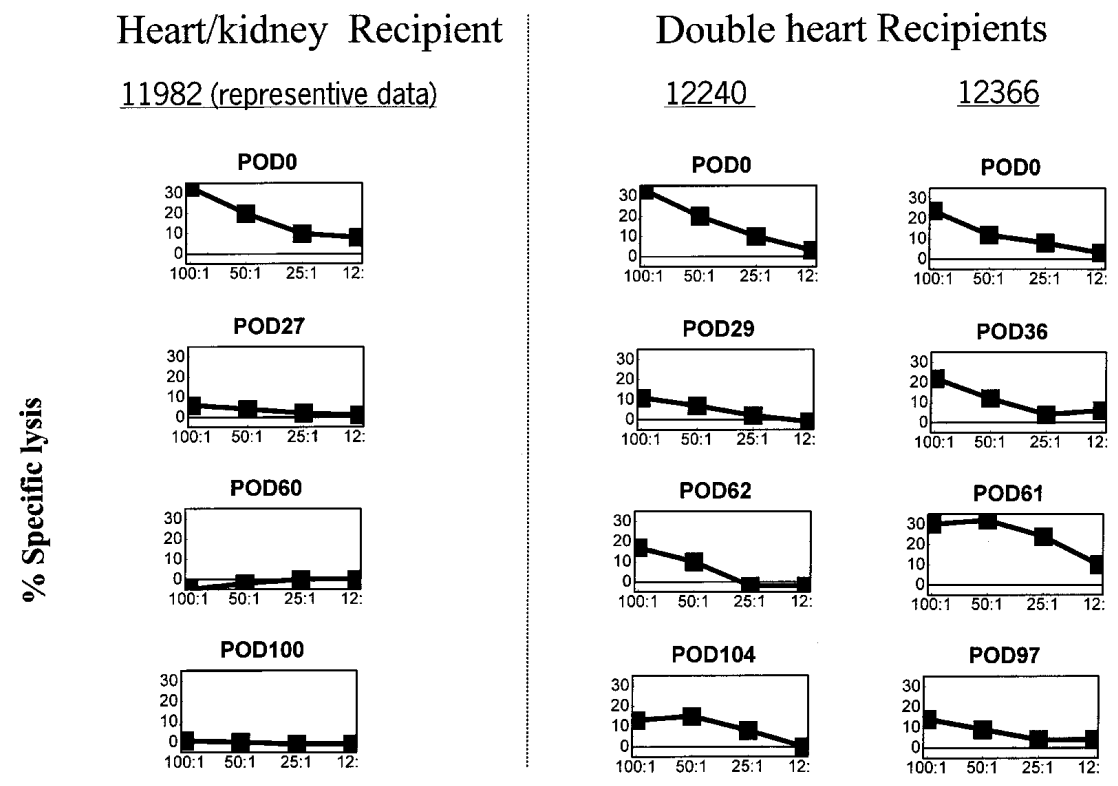

Fig 1. Antidonor CTL reactivity in euthymic double-heart recipients (right two columns) and representative data of antidonor CTL reactivity in a heart-kidney recipient (left column). E:T ratio, Effector cell/target cell ratio.

added, and cells were incubated for 30 minutes at $4^{\circ} \mathrm{C}$. After a further wash, phycoerythrin-streptavidin was added and incubated for 10 minutes to stain the biotinylated antibody. Two milliliters of $1 \times$ FACS lysing solution (Becton Dickinson) was then added to each tube to lyse red blood cells. The tubes were placed in a vortex and then incubated for 10 minutes at room temperature. The tubes were then placed in a vortex once more to ensure complete lysis of red blood cells before centrifugation. The cells were washed once and analyzed by FACScan.

\section{Results}

The effect of double-heart transplantation on tolerance and CAV. $\mathrm{We}^{10}$ have previously reported that isolated heart allografts transplanted across a class I disparity in miniature swine treated with a 12day course of CyA (POD 0-11) had florid coronary intimal proliferation by POD 28 and were rejected by POD 55 (Table I). In contrast, hearts cotransplanted with a kidney from the same class I disparate donor survived long term without the development of vascular lesions (Table I). ${ }^{10}$ To determine whether the specific unresponsiveness to heart allografts induced by combined heart-kidney cotransplantation was due to an increase in donor antigen load or to an effect specific to the kidney allograft, we performed doubleheart transplantation. Each recipient received two hearts that were MHC matched to each other but class I mismatched to the host.
The two recipients of double-heart allografts that were not thymectomized (Nos. 12240 and 12366) maintained their allografts long term (later than POD 190 and 197, respectively), which was similar to euthymic heart-kidney recipients (Table I). However, marked differences were observed between euthymic double-heart recipients and euthymic heart-kidney recipients in the development of in vitro parameters of alloresponsiveness and occurrence of both acute and chronic rejection histologically. Whereas heart-kidney recipients lost antidonor cytotoxic T lymphocyte (CTL) reactivity by POD 30, the euthymic double-heart recipients maintained antidonor CTL reactivity long term (Fig 1). Both euthymic double-heart recipients had antidonor IgM between PODs 20 and 30 (data not shown), whereas heart-kidney recipients never had a humoral alloresponse. ${ }^{10}$ Heart-kidney recipients never had significant interstitial rejection of either allograft and never had CAV. However, both heart allografts in euthymic double-heart recipients showed moderate interstitial mononuclear cell infiltrate by POD 60 and exhibited significant CAV by POD 30 (Table I and Fig 2, A).

Previous studies from our laboratory have suggested that the thymus plays a critical role in the induction of tolerance in miniature swine. ${ }^{13,24}$ To determine whether the prolongation of cardiac allograft survival in the double-heart recipients was dependent on the thymus, complete thymectomy was performed 3 weeks before 

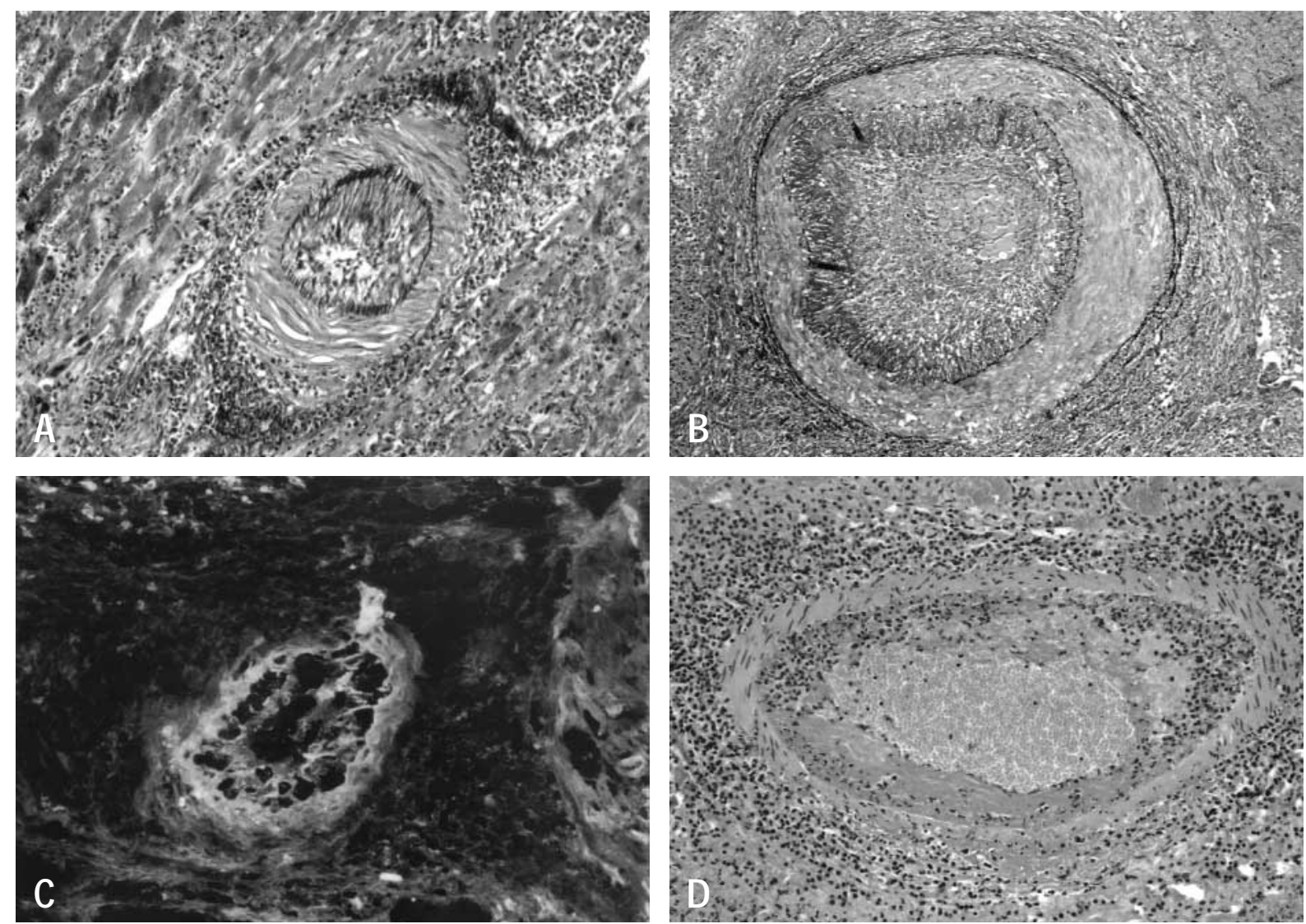

Fig 2. Representative histologic findings of MHC class I disparate heart grafts of recipients bearing double-heart grafts. A, A euthymic recipient on POD 60 exhibited moderate mononuclear cell infiltration along with CAV (hematoxylin and eosin staining). B, A thymectomized recipient on POD 63 exhibited severe mononuclear cell infiltration along with development of CAVs (hematoxylin and eosin staining). C, Immunohistochemical analysis of the deposition of IgG alloantibodies on the endothelium of coronary arteries in transplanted hearts in a thymectomized recipient on POD 63 (anti-swine IgG FITC). D, Histologic findings of MHC class I disparate heart graft of single-heart recipients with high-dose donor PBL infusion exhibited moderate mononuclear cell infiltration along with CAV on postoperative day 47 (hematoxylin and eosin staining).

transplantation in two double-heart recipients (Nos. 12688 and 12949). In contrast to euthymic recipients, both thymectomized double-heart recipients had rejection of their heart grafts in less than 100 days (PODs 63 and 96, respectively; Table I). The stronger alloresponses mounted by thymectomized double-heart recipients was reflected in in vitro studies and graft histology. At necropsy, cardiac allografts from thymectomized double-heart recipients demonstrated a greater degree of intimal proliferation in both large and small vessels compared with hearts removed from euthymic double-heart recipients at necropsy (Table I and Fig 2, $B$ ). The thymectomized double-heart recipients also exhibited stronger antidonor CTL responses after transplantation than the euthymic double-heart recipients (compare Fig 1 and Fig 3). Finally, allo-IgG antibody deposition on the endothelium of small donor coronary arteries from the rejected allografts of thymectomized double-heart recipients was more extensive than that seen on the coronary endothelium from rejected allografts of euthymic double-heart recipients (Fig 2, C). These data suggest that the host thymus plays an important role in the prolongation of graft survival in recipients of double-heart transplantation and corroborates earlier studies that demonstrated the important role the thymus plays in rejection responses in miniature swine. ${ }^{13,24}$

The effect of donor PBL infusion on tolerance and CAV. We next investigated whether the augmentation in donor antigen load conferred by a high-dose infusion 
of donor PBLs could prolong allograft survival in euthymic recipients of isolated class I disparate hearts. Two recipients (Nos. 12952 and 12922) received class I-mismatched isolated heart allografts along with an intravenous infusion of fresh donor PBLs $(2.5 \times$ $10^{9} / \mathrm{kg}$ ) on POD 0. Donor lymphocyte macrochimerism was assessed by means of FACS with a donor SLA class I-specific mAb. Both recipients exhibited high levels of macrochimerism during the period of CyA administration (PODs 0-12; Fig 4). However, the levels of macrochimerism declined shortly thereafter and were undetectable by POD 33 . The majority of donor cells in the lymphocyte gate were $\mathrm{CD}^{+} \mathrm{T}$ cells (Fig 4, dashed line). Further phenotypic analysis demonstrated that both $\mathrm{CD}^{+} \mathrm{T}$ cells and $\mathrm{CD} 8^{+} \mathrm{T}$ cells were present in the early period $(<14$ days; Fig $5, A)$. However, by POD 26, only $0.1 \%$ of donor T cells expressed the CD4 marker (Fig 5, B). In addition, $70 \%$ of donor lymphocytes on POD 26 were $\mathrm{CD}^{+} / \mathrm{CD} 2^{-}$, suggesting that these were $\gamma \delta$ T cells (Fig 5, B).

Hearts transplanted into recipients treated with highdose donor PBLs had high-grade interstitial rejection and were fully rejected by PODs 47 and 63 (Table I). At necropsy, extensive mononuclear cell infiltrates were observed in the heart allografts from both recipients. One animal exhibited marked CAV, and the other exhibited severe endotheliitis (Table I). Both recipients had antidonor class I IgM and IgG by the time of rejection (data not shown). Although both recipients lost donor-specific responsiveness in CML assays on POD 30 , by the time of allograft rejection, both recipients had regained antidonor CTL reactivity (Fig 6). These data indicate that augmentation of donor antigen load by high-dose donor PBL infusion and achieving a state of high-level, albeit short-lived, peripheral macrochimerism were not as effective as donor kidney cotransplantation in prolonging cardiac allograft survival and preventing CAV.

\section{Discussion}

$\mathrm{We}^{10}$ have previously reported that when cardiac allograft recipients were simultaneously cotransplanted with a donor-specific kidney graft, the hosts became tolerant to both allografts. Furthermore, the state of tolerance that resulted from heart-kidney cotransplantation not only led to long-term survival of the heart allografts but also prevented the development of CAV. One hypothesis to explain the tolerogenic effect of the kidney allograft is that specialized cells (possibly bone marrow-derived dendritic cells) residing in the kidney migrate to the thymus, where they induce and maintain tolerance. This could occur either by means of central

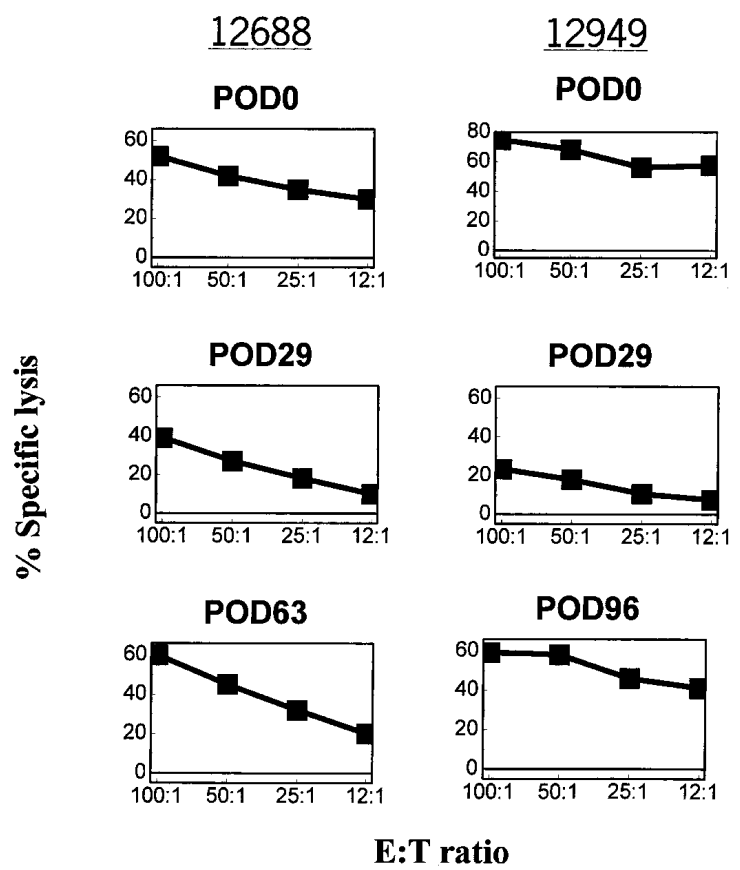

Fig 3. Antidonor CTL reactivity in thymectomized doubleheart recipients. E:T ratio, Effector cell/target cell ratio.

deletional mechanisms (ie, donor dendritic cells or host antigen-presenting cells with donor antigen migrating to the thymus and educating host T-cell precursors or reeducating mature circulating $\mathrm{T}$ cells $)^{25}$ or peripheral mechanisms (ie, thymic-derived, host regulatory cells that traffic back to the allograft and mediate local suppression). According to this hypothesis, a heart allograft alone would not induce unresponsiveness because it does not have sufficient numbers of these immunoregulatory cells.

An alternative hypothesis is that cotransplantation of the kidney allograft simply augments the load of donor antigen presented to the host at the time of heart transplantation and results in antigen-induced unresponsiveness, which is similar to the "blood transfusion effect." 14 To address this issue, we compared heart-kidney transplantation with double-heart transplantation. We demonstrated that, like recipients bearing a heart and kidney, recipients bearing two hearts accepted their allografts over the long term. However, unlike heartkidney recipients, the double-heart recipients maintained antidonor CTL reactivity, had alloantibodies, and had significant CAV, indicating that tolerance had not been achieved. One interpretation of these results is that an augmentation in donor antigen load was able to effectively delay acute rejection but that a kidney-related mechanism was necessary for inducing rapid and 

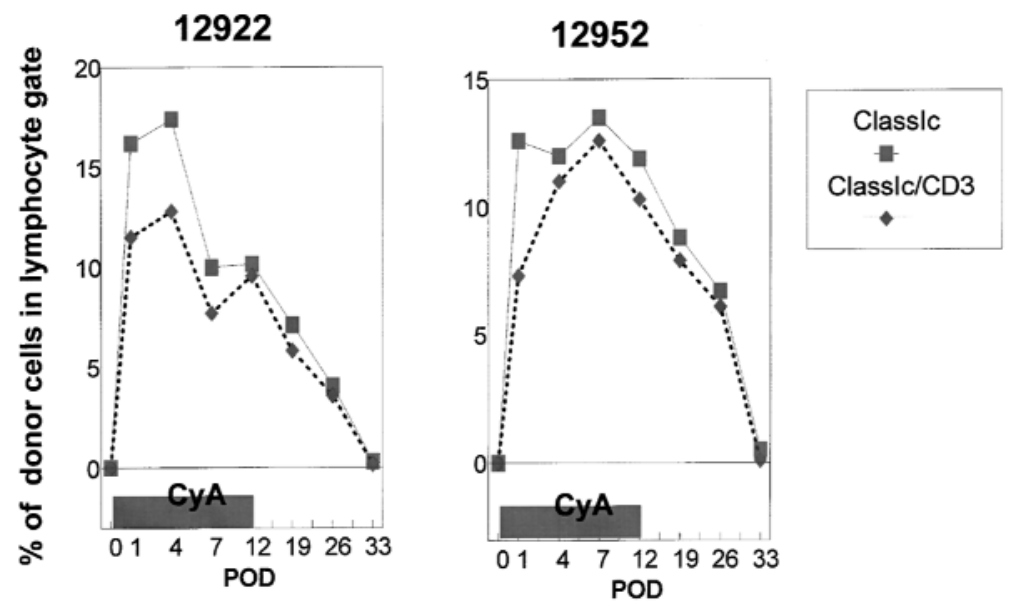

Fig 4. Flow cytometric analysis of lymphopoietic donor macrochimerism in whole blood from recipients bearing an isolated class I disparate heart allograft after high-dose donor PBL infusion.

\section{POD 4}
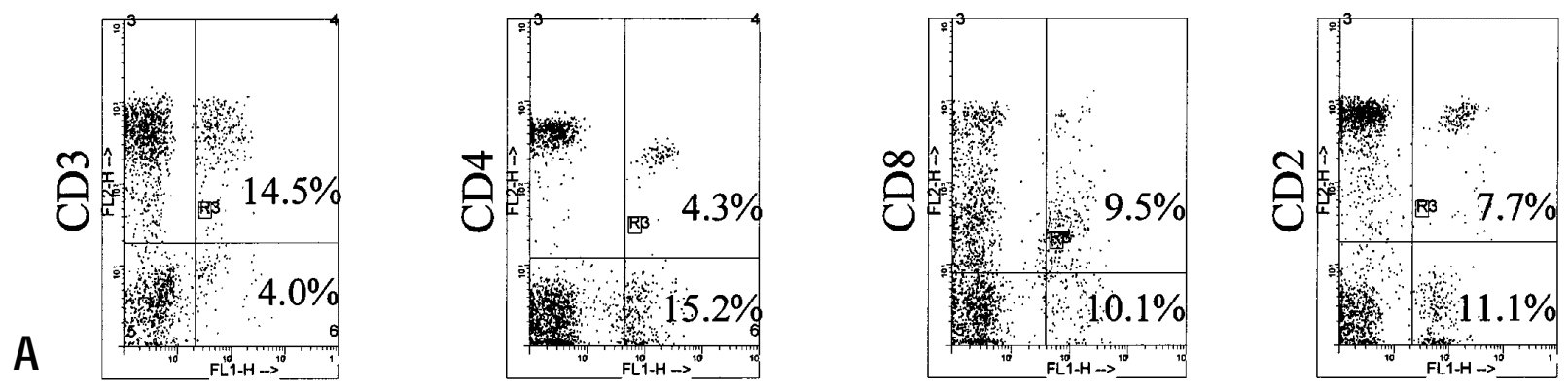

\section{POD26}
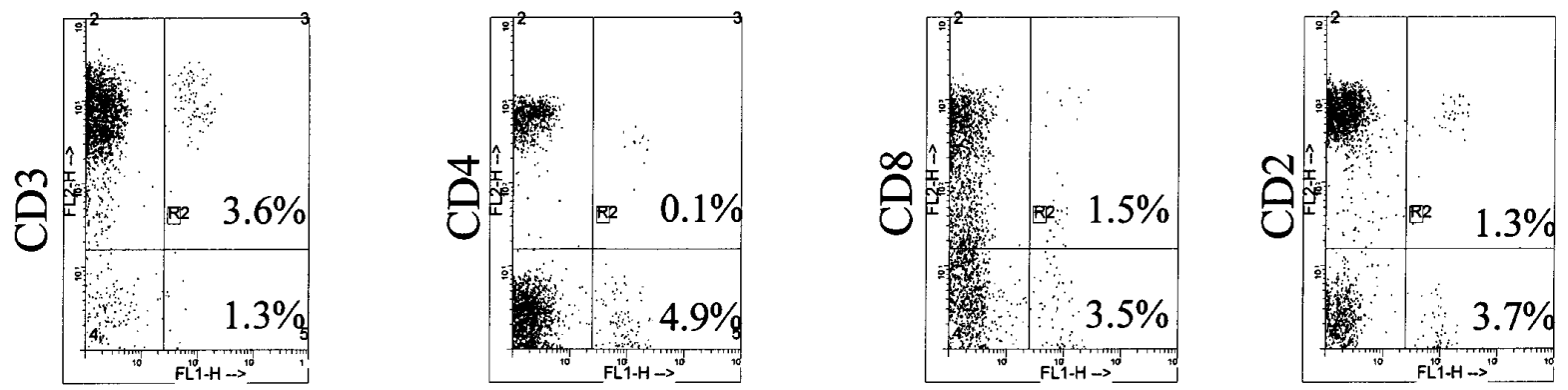

B

\section{Class $\mathrm{I}^{\mathrm{c}}$ (donor type)}

Fig 5. Phenotypic analysis of donor chimerism by FACS in the recipient (No. 12922) bearing MHC class I disparate isolated heart allograft with high-dose donor PBL infusion. $\mathbf{A}, \mathrm{CD} 4^{+}$cells or $\mathrm{CD} 8^{+}$donor cells were seen on POD 4. B, Only $0.1 \%$ of donor T cells expressed CD4, and $70 \%$ of donor lymphocytes were $\mathrm{CD}^{+} / \mathrm{CD} 2^{-}$cells on POD 26. 


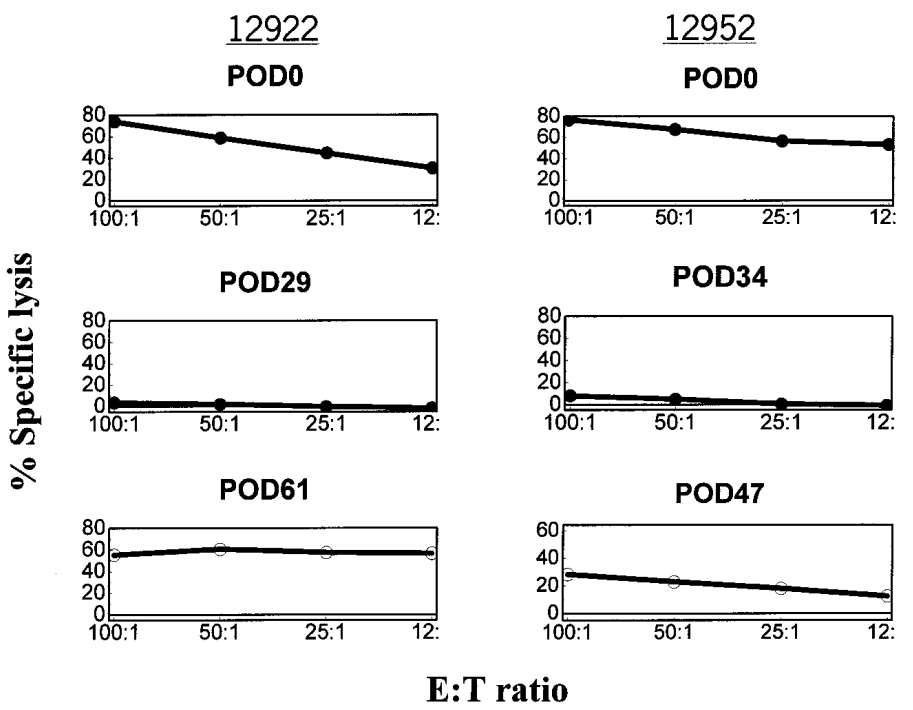

Fig 6. Anti-donor CTL reactivity in recipients of isolated class I disparate heart allografts after high-dose donor PBL infusion. E:T ratio, Effector cell/target cell ratio.

stable tolerance and preventing the vascular lesions of chronic rejection. The inability of high-dose donor leukocyte infusion to facilitate tolerance and prevent CAV supports this theory.

The protective role that a donor-specific kidney plays in cardiac allograft survival has been reported in both experimental ${ }^{10}$ and clinical transplantation, ${ }^{26}$ but the mechanisms underlying this effect have not been elucidated. As we mentioned above, one hypothesis to explain the tolerogenic effect of the kidney allograft is that renal parenchyma contains a greater number of regulatory cells (possibly dendritic cells-passenger leukocytes) that can migrate from the donor kidney to the host thymus and mediate central tolerance. Support for this theory comes from the fact that thymectomizing recipients of isolated kidney allografts ${ }^{13}$ or heartkidney allografts ${ }^{24}$ prevented the induction of rapid and stable tolerance. However, in the present study doubleheart recipients that were thymectomized exhibited a more aggressive rejection response than euthymic double-heart recipients, despite the absence of a donor kidney. Similarly, we have previously shown that singleheart recipients that were thymectomized also exhibited a more aggressive rejection response than euthymic single-heart recipients. ${ }^{24}$ In addition, thymectomized heart-kidney recipients had CAV and rejected their cardiac allografts in a similar fashion to euthymic single-heart recipients. ${ }^{24}$ These results suggest that the detrimental effect thymectomy has on graft survival may also be related to the loss of recent thymic emigrants independent of kidney-specific mechanisms.
These thymic emigrants could represent regulatory cells, which traffic from the host's thymus to the donor organ irrespective of the presence of a kidney allograft, and induce tolerance peripherally by downregulating alloreactive cells within the graft. Such peripheral tolerance could be mediated by suppressive regulatory mechanisms, by a change in cytokine milieu, or both. There is evidence from several groups that the induction of tolerance by CyA is mediated by regulatory $\mathrm{T}$ cells and requires a functioning thymus. ${ }^{27-29} \mathrm{We}$ have also demonstrated that the maintenance of tolerance to renal allografts in our model is associated with the presence of peripheral regulatory cells. ${ }^{30}$

To separate the beneficial effects that may be mediated by kidney-independent recent thymic emigrants from the effects of kidney-derived cells that traffic to the host thymus, we plan to perform thymectomy in heart-kidney recipients on POD 0 instead of 3 weeks after transplantion. Our hypothesis is that the doubleheart experiments imply an additional role for recent thymic emigrants, whereas the kidney-heart experiments imply a role for kidney-derived regulatory cells. If this hypothesis is true, then the difference in survival times between the double-heart versus single-heart recipients (most of which is lost when thymectomy is performed on day -21) should still be seen if thymectomy is performed on day 0 , whereas the difference in survival times between between kidney plus heart versus single heart alone (most of which is also lost when thymectomy is performed on day -21) should also be lost if thymectomy is performed on day 0 . To charac- 
terize the role of kidney-derived cells on the induction of tolerance to heart allografts, we plan to extract, phenotype, and infuse different kidney cell populations into heart transplant recipients and study their effects on CAV. Finally, even though augmentation of donor antigen load did not lead to tolerance, it did prolong graft survival significantly.

In conclusion, the present study demonstrates that although an augmentation of donor antigen introduced into the host at the time of transplantation may have beneficial effects in suppressing acute rejection, it does not appear to be the sole mechanism by which cotransplantation of a heart and a kidney induces tolerance. Other kidney- and thymus-related mechanisms seem to play an important role in the abrogation of the vascular lesions of chronic rejection.

We thank Drs David K. C. Cooper and Richard Lee for critical review of the manuscript and Mr J. Scott Arn for herd management and quality control typing. We also acknowledge the generosity of the Novartis Pharmaceutical Corporation, which kindly provided cyclosporine, and of Schering-Plough Animal Health for providing flunixamine.

\section{REFERENCES}

1. Madsen JC, Sachs DH, Fallon JT, Weissman NJ. Cardiac allograft vasculopathy in partially inbred miniature swine. I. Time course, pathology, and dependence on immune mechanisms. J Thorac Cardiovasc Surg 1996;111:1230-9.

2. Choo JK, Seebach JD, Nickeleit V, et al. Species differences in the expression of major histocompatibility complex class II antigens on coronary artery endothelium: implications for cell-mediated xenoreactivity. Transplantation 1997;64:1315-22.

3. Kirkman RL. Of swine and men: organ physiology in different species. In: Hardy MA, ed. Xenograft 25. 1st ed. Amsterdam: Elsevier; 1989. p. 125-39.

4. Fuster V, Badimon L, Badimon JJ, Ip JH, Chesebro JH. The porcine model for the understanding of thrombogenesis and atherogenesis. Mayo Clin Proc 1991;66:818-31.

5. Madsen JC. Cardiac allograft vasculopathy in miniature swine: utility of a large animal model. Graft 1998;1(Suppl II):41-4.

6. Russell PS, Chase CM, Winn HJ, Colvin RB. Coronary atherosclerosis in transplanted mouse hearts. I. Time course and immunogenetic and immunopathological considerations. Am J Pathol 1994;144:260-74.

7. Shi C, Lee WS, He Q, et al. Immunologic basis of transplantassociated arteriosclerosis. Proc Natl Acad Sci U S A 1996;93: 4051-6.

8. Cramer DV, Qian S, Harnaha J, et al. Cardiac transplantation in the rat. I. The effect of histocompatibility differences on graft atherosclerosis. Transplantation 1989;47:414-9.

9. Allan JS, Choo JK, Vesga L, et al. Cardiac allograft vasculopathy is abrogated by anti-CD8 monoclonal antibody therapy. Ann Thorac Surg 1997;64:1019-25.

10. Madsen JC, Yamada K, Allan JS, et al. Transplantation tolerance prevents cardiac allograft vasculopathy in major histocompatibil- ity complex class I-disparate miniature swine. Transplantation 1998;65:304-13.

11. Rosengard BR, Ojikutu CA, Guzzetta PC, et al. Induction of specific tolerance to class I disparate renal allografts in miniature swine with cyclosporine. Transplantation 1992;54:490-7.

12. Gianello PR, Fishbein JM, Sachs DH. Tolerance to primarily vascularized allografts in miniature swine. Immunol Rev 1993;133: 19-44.

13. Yamada K, Gianello PR, Ierino FL, et al. Role of the thymus in transplantation tolerance in miniature swine. I. Requirement of the thymus for rapid and stable induction of tolerance to class I-mismatched renal allografts. J Exp Med 1997;186:497-06.

14. Madsen JC, Superina RA, Wood KJ, Morris PJ. Immunological unresponsiveness induced by recipient cells transfected with donor MHC genes. Nature 1988;332:161-4.

15. Sachs DH, Leight G, Cone J, Schwartz S, Stuart L, Rosenberg S. Transplantation in miniature swine. I. Fixation of the major histocompatibility complex. Transplantation 1976;22:559-67.

16. Kirkman RL, Colvin MW, Flye GS, et al. Transplantation in miniature swine. VI. Factors influencing survival of renal allografts. Transplantation 1979;28:18-23.

17. Steinbrüchel DA, Nielsen B, Salomon S, Kemp E. A new model for heterotopic heart transplantation in rodents: graft atrial septectomy. Transplant Proc 1994;26:1298-9.

18. Billingham ME, Cary NR, Hammond ME, et al. A working formulation for the standardization of nomenclature in the diagnosis of heart and lung rejection: heart rejection study group. J Heart Transplant 1990;9:587-93.

19. Lurie KG, Billingham ME, Jamieson SW, Harrison DC, Reitz BA. Pathogenesis and prevention of graft arteriosclerosis in an experimental heart transplant model. Transplantation 1981;31: 41-7.

20. Colvin RB. The renal allograft biopsy. Kidney Int 1996;50:106982.

21. Kirkman RL, Colvin RB, Flye MW, Williams GM, Sachs DH. Transplantation in miniature swine. VII. Evidence for cellular immune mechanisms in hyperacute rejection of renal allografts. Transplantation 1979;28:24-30.

22. van Es AA, Balner H. Serologic matching for D locus antigens improves kidney allograft survival in rhesus monkeys. Transplantation 1978;26:187-93.

23. Harrison MR, MacPhail B, Gurley JC, et al. Usefulness of color Doppler flow imaging to distinguish ventricular septal defect from acute mitral regurgitation complicating acute myocardial infarction. Am J Cardiol 1989;64:697-701.

24. Yamada K, Choo JK, Allan JS, et al. The effect of thymectomy on tolerance induction and cardiac allograft vasculopathy in a miniature swine heart/kidney transplantation model. Transplantation 1999;68:485-91.

25. Agus DB, Surh CD, Sprent J. Reentry of T cells to the adult thymus is restricted to activated T cells. J Exp Med 1991;173:1039-46.

26. Narula J, Bennett LE, DiSalvo TG, Hosenpud JD, Semigran MJ, Dec GW. Outcomes in recipients of combined heart-kidney transplantation. Multi-organ, same-donor transplant study of the ISHLT/UNOS scientific registry. Transplantation 1997;63:86167.

27. Hutchinson IF, Shadur CA, Duarte JSA, Strom TB, Tilney NL. Cyclosporine A spares selectively lymphocytes with donor-specific suppressor characteristics. Transplantation 1981;32:210-6.

28. Hall BM, Pearce NW, Gurley KE, Dorsch SE. Specific unresponsiveness in rats with prolonged cardiac allograft survival 
after treatment with cyclosporine. III. Further characterization of the CD4+ suppressor cell and its mechanisms of action. J Exp Med 1990;171:141-57.

29. Nagao T, White DJG, Calne RY. Kinetics of unresponsivess induced by a short course of cyclosporine A. Transplantation 1982;33:31-7.
30. Ierino FL, Yamada K, Hatch T, Rembert J, Sachs DH. Peripheral tolerance to class I mismatched renal allografts in miniature swine: donor antigen-activated peripheral blood lymphocytes from tolerant swine inhibit antidonor CTL reactivity. J Immunol 1999;162:550-9.

\section{ON THE MOVE? \\ Send us your new address at least six weeks ahead}

Don't miss a single issue of the journal! To ensure prompt service when you change your address, please photocopy and complete the form below.

Please send your change of address notification at least six weeks before your move to ensure continued service. We regret we cannot guarantee replacement of issues missed due to late notification.

\section{JOURNAL TITLE:}

Fill in the title of the journal here.

\section{OLD ADDRESS:}

Affix the address label from a recent issue of the journal here.

\section{NEW ADDRESS:}

Clearly print your new address here.

Name

Address

City/State/ZIP

OR FAX TO:

314-432-1158

Periodical Subscription Services

Mosby, Inc.

11830 Westline Industrial Dr.

St. Louis, MO 63146-3318

N/ Mosby
OR PHONE:

1-800-453-4351

Outside the U.S., call

314-453-4351 